\title{
Chemistry Student Perceptions of Transferable \& Workplace Skills Development
}

\author{
Dylan P. Williams* \& Sandeep Handa \\ University of Leicester \\ *Corresponding Author: dpw10@le.ac.uk
}

Keywords: Transferable skills, Workplace skills, Employability, Chemistry education

\begin{abstract}
The perceptions of transferable and workplace skills development of year one and two chemistry undergraduate students at the University of Leicester were measured using two questionnaires. This group of students is taught by a variety of approaches including Problem and Context Based Learning (C/PBL). Over $60 \%$ of respondents agreed that all discipline specific and transferable skills included in the first questionnaire were important skills for chemistry graduates to have. The perceived importance of most discipline specific skills does not vary between year groups, but there are small increases in perceived importance for most transferable skills. In a separate questionnaire, first year students were asked to rate their skills development following a series of Context and Problem Based Learning (C/PBL) activities. "Problem solving", "time management", "working in a team" and "oral communication" were the most developed skills based on student responses. This element of the study also provided evidence to suggest that students believe that the "real-world", authentic nature of C/PBL problems may be an important factor in determining the extent of skills development.
\end{abstract}

\section{Introduction}

In 2010 a Higher Education Academy (HEA) report highlighted a gap between the skills being taught as part of chemistry degree programmes and the skills most commonly used by graduates of the subject (Hanson and Overton, 2010). In order to address the needs of an increasingly diverse student body and to make better use of new technologies, a number of innovative teaching approaches have been developed and used in chemistry programmes. The need for innovative, approaches has intensified as a consequence of the 2010 report and recent studies into the effectiveness of these approaches (Freeman et al., 2014). A range of different approaches including Context and Problem Based Learning (C/PBL) (Belt, et al., 2002, Summerfield, et al., 2003 \& Overton, 2007), flipped teaching (Lancaster and Read, 2013, Seery, 2013) and Peer Assisted Learning (PAL) have been used. A number of these share a common goal of developing studentcentred learning experiences which integrate the development of both discipline-specific and transferable skills.

The Chemistry degree programme at the University of Leicester introduced C/PBL approaches in 2007 (Williams, et al., 2010) and since that time the approaches have been embedded throughout the programme (Williams, 2015 Williams, 2016). C/PBL is a team-based approach (Savery \& Duffy, 1995; Raine \& Symons, 2005) which requires students to collaborate on the solution to an open-ended problem based on a realistic scenario (Honebein, et al., 1993; Engel, 1997). This approach lends itself to the development of transferable skills training in the core subject curriculum (Kelly and Finlayson, 2007) as it can help students make the transition from declaration of knowledge and solving algorithmic problems to developing solutions to 
complex, open-ended problems which integrate different areas of discipline content as well as non-discipline content. For example, a problem based on the development of sustainable approaches to generating power may combine thermodynamics, nuclear chemistry, electrochemistry as well as relevant geographical, legal and political considerations. The assessment of $\mathrm{C} / \mathrm{PBL}$ problems is typically aligned with the context of the problem which results in opportunities to develop oral and written presentation skills, team working skills as well as numeracy and computer literacy.

This paper presents the findings from the initial first stage of this project. The aim of this phase was to measure the variation in student perceptions of transferable skills throughout a chemistry degree programme. Chemistry students at the University of Leicester were asked to complete a questionnaire which measured their attitudes towards transferable skills at several different stages of the degree programme. An additional questionnaire was deployed at the end of a ten week long series of year one C/PBL activities to record student confidence levels in key transferable skills after completion of these learning opportunities. The key research question addressed by this phase of the project was:

Do student attitudes towards the importance of transferable/workplace skills development change over the period of study of a degree?

The work described here will be built on in subsequent years by comparing responses from students who have experienced C/PBL approaches with those who have experienced other pedagogical approaches.

The ultimate aim of the project is to draw comparisons between the responses given by students studying different chemistry programmes in order to establish whether the pedagogical approaches adopted by individual programmes had an impact on the reported attitudes of students towards these skills and on the level of skills development reported by students in year one of each programme. The whole project is yet to be completed but the findings reported in this paper will feed into this larger study. The overall research question addressed by the larger study is:

Are student attitudes towards the importance of transferable/workplace skills development related to the teaching and learning approaches used?

\section{Methodology}

The initial phase of this project took place during the 2014/15 and 2015/16 academic years at the University of Leicester. The study group included all students in years one to three of the Chemistry, Chemistry with Forensic Science and Pharmaceutical Chemistry degree programmes. All students on these degree programmes have experienced C/PBL approaches as integrated components of modules throughout the programme.

The research tools used in this phase of the project took the form of questionnaires which were validated using a small group of volunteer students from the undergraduate cohort $(\mathrm{N}=5)$ in the 2014-15 academic year as well as a small group of teaching staff in the summer of 2015. The validation ensured that the questionnaire could be completed in the amount of time available, that the questions were worded in a way that was easy to understand for chemistry undergraduates and that the responses generated could be used meaningfully by the research team.

\section{Questionnaire 1 - Student Attitudes towards Skills Development}

Questionnaire 1 used a series of Likert-type response questions which measured student attitudes towards a range of transferable and subject-specific skills. The skills included in this questionnaire (see table 1) were based on those included in the Hanson and Overton study but a small number were added in order to address specific features of the chemistry degree programmes taught at Leicester. Students were asked to rate how important each skill was on a five point scale (very important, important, neutral, unimportant and very unimportant).

In order to maximise response rate, questionnaires were distributed in teaching laboratory sessions which all students were required to attend. Students were also 
provided with a description of the project, details of how their data would be stored, what analysis and dissemination would be performed and details of the ethical approval of the project. Reasonable response rates were achieved from both year one and year two groups. In year one, 88 students responded to the questionnaire out of a total of 117. In year two, 67 students responded out of a total of 92 . Only 13 students from year 3 responded from a total of 102) so this data has been omitted.

\begin{tabular}{|c|}
\hline Analytical techniques \\
\hline Chemical terminology \\
\hline Fundamental chemical principles \\
\hline Independent learning ability \\
\hline Information Retrieval Skills \\
\hline Inorganic compounds and reactions \\
\hline Interpretation of experimental data \\
\hline Kinetics of chemical change \\
\hline Numeracy and computational skills \\
\hline Oral presentation skills \\
\hline Problem-solving skills \\
\hline Principles of thermodynamics \\
\hline Report Writing Skills \\
\hline Manipulative practical skills \\
\hline Organic compounds and reactions \\
\hline Planning and design of experiments \\
\hline Safe handling of chemical materials \\
\hline Chemical instrumentation skills \\
\hline Team-working skills \\
\hline Time management and organisational skills \\
\hline Table 1 The skills included in \\
\hline questionnaire 1. \\
\hline
\end{tabular}

\section{Questionnaire 2 - Student Confidence Levels in Transferable Skills}

Questionnaire 2 was deployed at the end of a term-long series of C/PBL activities which take place at the start of year one of the chemistry degree programmes at Leicester (Williams, et al., 2010). Academics in the department had observed an improvement in students' transferable skills following the introduction of C/PBL approaches to the programme in 2007, so the aim of this questionnaire was to attempt to capture the impact on student confidence levels in these skills.

This questionnaire was deployed online as a Google Form in the 2014/15 and 2015/16 academic years. The response rate for the questionnaire was reasonable (119 students responded out of a total of 230 across the two academic years).

The questionnaire included a Likert-type scale question which asked students to rate their confidence levels in a number of core transferable skills (see table 2) based on their experience of $\mathrm{C} / \mathrm{PBL}$ at Leicester on a four point scale (very confident, confident, not very confident and skills not used). The questionnaire also included free text questions which invited students to nominate the skills they felt they had developed the most from the C/PBL experience and to make any additional comments on skills development that they felt were relevant.

\section{Results and Discussion}

\section{Questionnaire 1 \\ Please rate how important you believe the following skills/knowledge to be for a chemistry graduate}

Although no distinction was made between transferable skills, theoretical chemical skills and practical skills in the questionnaire (in fact, the order the skills appeared in was randomised to try to avoid biasing responses to non-discipline specific skills), we have chosen to categorise the skills in these groups for the purpose of this analysis (Figures 1 to 3 ).

In general it is worth noting that no skill was rated as important or very important by less than $61.4 \%$ of respondents in either year group. All theoretical skills were rated as important or very important by $81.8 \%$ or more of respondents and all practical skills by $80.6 \%$ or more of respondents. The level of importance that students place on theoretical skills decreases in five out of seven categories between years one and two (Figure 2). The level of perceived importance of practical skills shows very little variation between years one and two (Figure 3).

For transferable skills (Figure 1), the level of importance increases between years one and two in seven out of eight categories. It is possible that the increase in perceived importance of transferable skills and the 
Chemistry Student Perceptions of Transferable \& Workplace Skills Development

simultaneous decrease in perceived importance of many theoretical chemistry skills may be due to some students recognising the fact that they want to follow a career path not related to the subject, greater levels of student awareness of employer expectations (e.g. following careers sessions which take place towards the end of year one and at the start of year two) and a better appreciation of the importance of transferable skills in chemical problem solving (e.g. due to more experience of C/PBL problems).

\section{Transferable Skills Comparison}

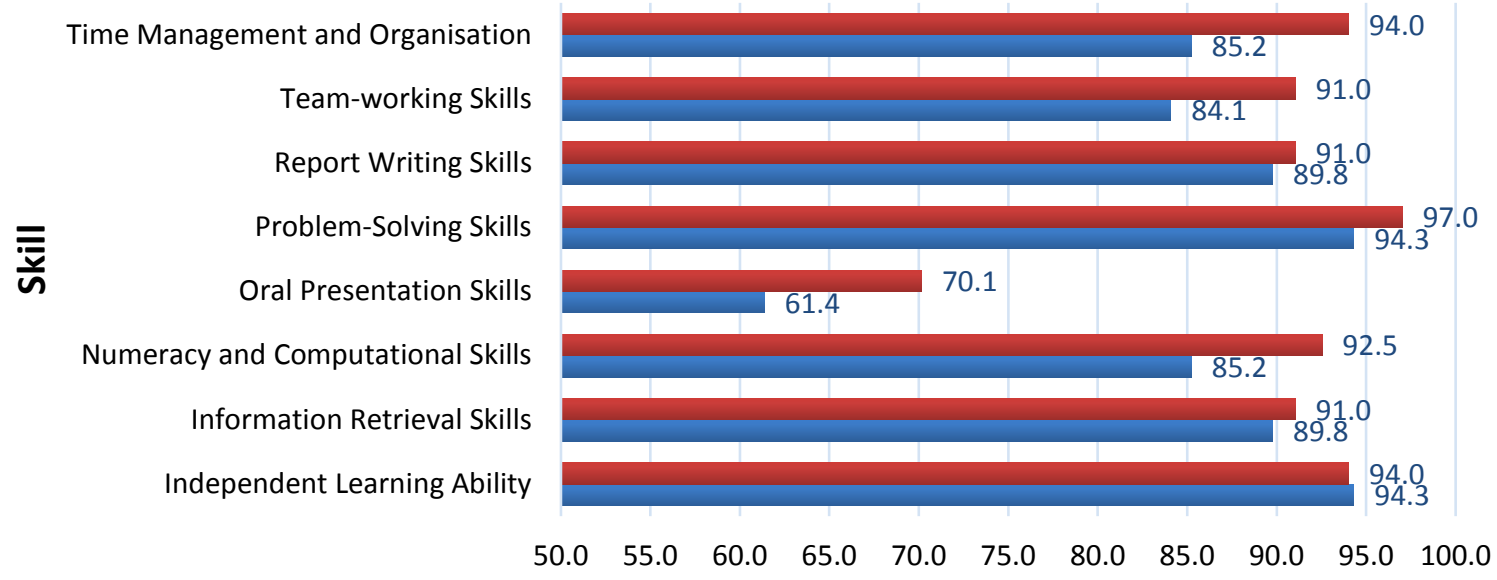

Percentage agreement $\quad$ Year $2 \quad$ Year 1

Figure 1 Percentage of year $1(\mathrm{~N}=88)$ and year $2(\mathrm{~N}=67)$ respondents who stated that the following transferable skills and/or knowledge were important or very important for chemistry graduates.

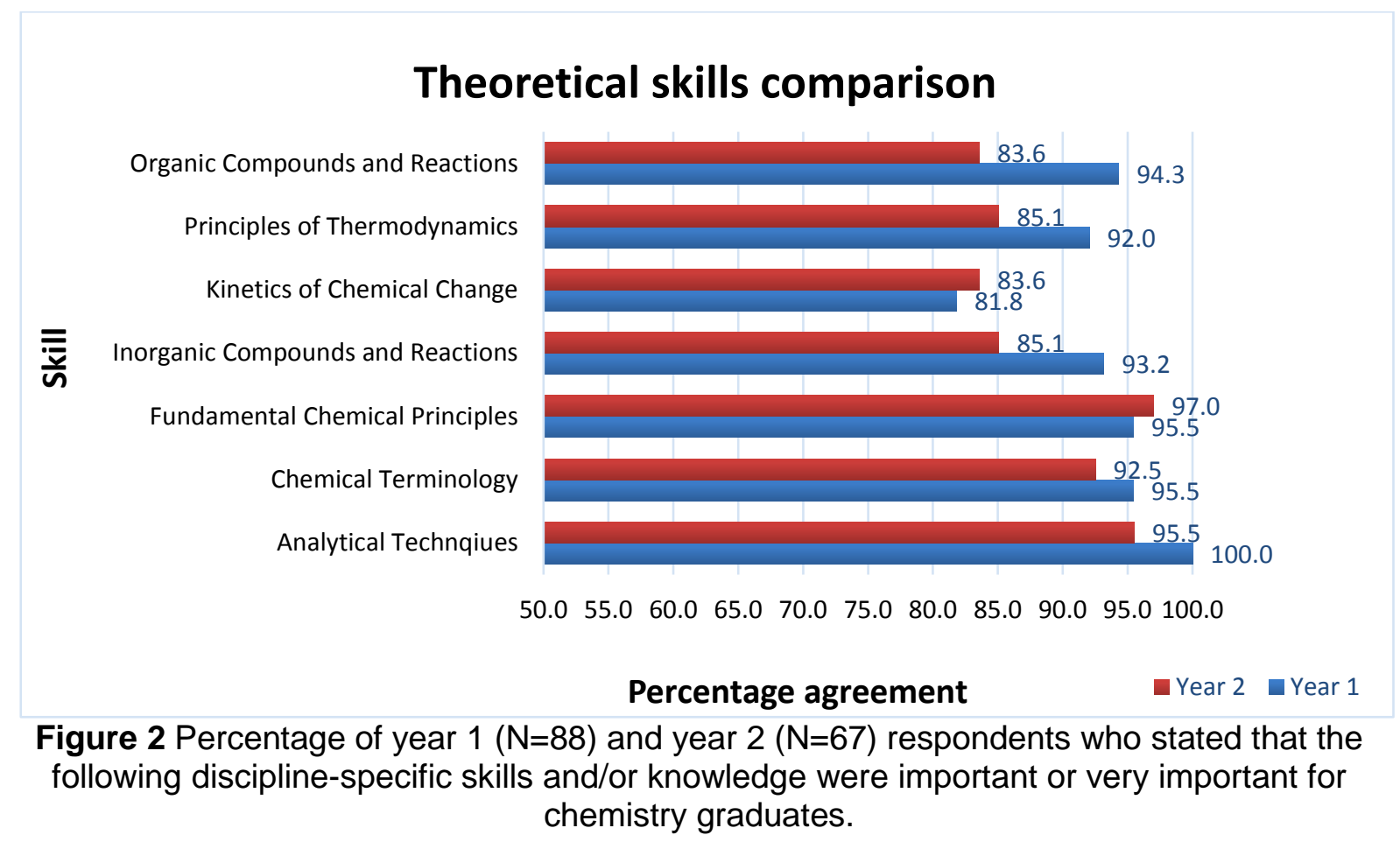




\section{Practical skills comparison}

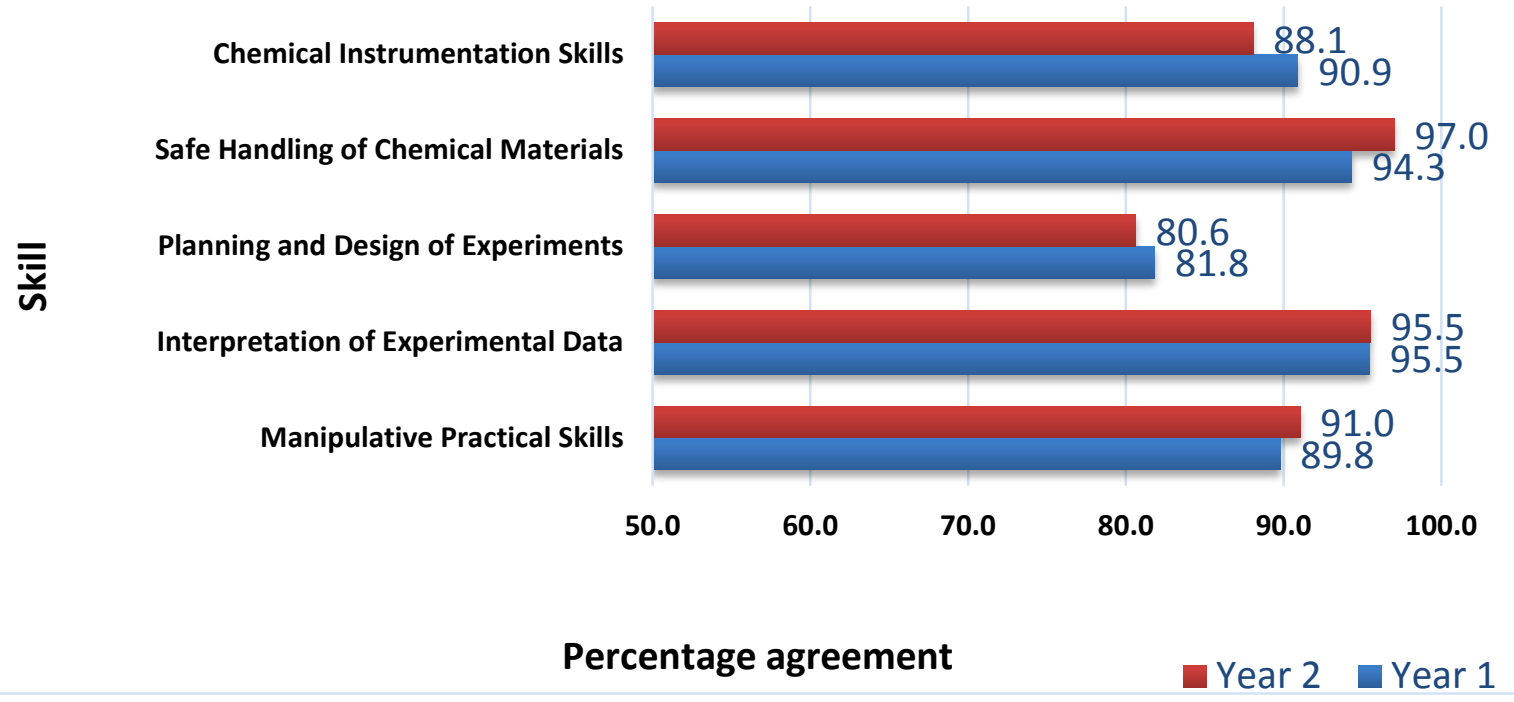

Figure 3 Percentage of year $1(\mathrm{~N}=88)$ and year $2(\mathrm{~N}=67)$ respondents who stated that the following practical skills and/or knowledge were important or very important for chemistry graduates.

The perceived levels of importance of all discipline-specific skills reported by year one and two chemists at Leicester were higher than those reported by chemistry graduates in an earlier study (Hanson and Overton, 2010). The lowest level of response from both Leicester year groups was recorded for Oral Presentation Skills. This contrasts with the findings from the Hanson and Overton study, where graduates rated oral presentation skills as being more important than all discipline specific theoretical skills.

The ultimate aim of this study is to continue measuring responses to these questions at years three and four in order to verify whether student attitudes towards these skills vary gradually over time or, whether there is a sudden change in student perceptions, possibly due to a transformative experience.

\section{Questionnaire 2}

Considering your PBL experience to date, rate how much you think you have improved the following skills

Students were asked to rate their confidence levels in a variety of transferable skills based on their experience of a ten week long programme of C/PBL activities in semester one of year one at the University of Leicester (Figure 4). Over $70 \%$ of students agreed that the C/PBL experience had left them feeling very confident in all skills listed on the questionnaire apart from Scientific Method. The approach appears to be particularly effective at developing confidence in written communication skills, working as part of a team and solving problems.

Which three skills did you develop the most by doing C/PBL?

Students were invited to nominate the three skills which they felt they had developed the most from the C/PBL experience in a free text question. The responses were analysed using text analysis software to identify common themes and phrases (Table 2). The student responses support staff observations that the C/PBL experience helps improve complex problem solving, oral communication skills (a large part of the problem solving process is based on group discussion), team work and time management. 


\section{Skills Development in Year 1 C/PBL}

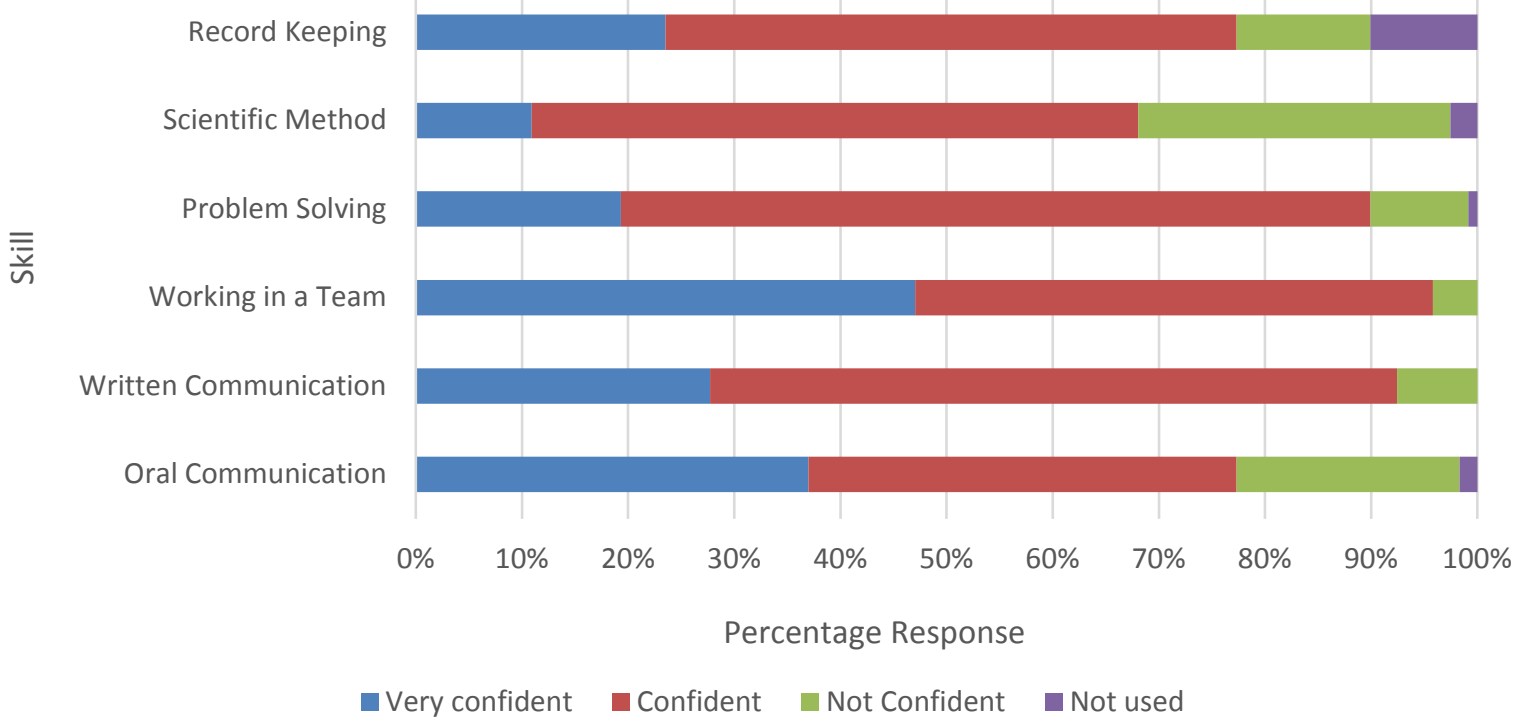

Figure 4 Responses to skills development questionnaire from year one students in 2014/15 and 2015/16 following a ten week first semester C/PBL activity ( $N=119)$.

\begin{tabular}{|ll|}
\hline \multicolumn{1}{|c|}{ Skill } & \multicolumn{1}{c|}{ Number of responses } \\
\hline "problem solving" & 54 responses \\
\hline "time management" & 35 responses \\
\hline "working in a team" & 31 responses \\
\hline "oral communication" & 29 responses \\
\hline "data analysis" & 16 responses \\
\hline
\end{tabular}

Table 2 The five skills that questionnaire respondents felt were developed the most by $\mathrm{C} / \mathrm{PBL}$ in year one of the chemistry degree programme at Leicester $(\mathrm{N}=119)$.

Students were also invited to make general comments about their personal development throughout the C/PBL component of the course. When discussing what students found useful about the C/PBL, the comments defined some of the experiences which appeared to be most productive in terms of skills development such as the context of the problem and the use of authentic assessment ("The C/PBL helped me develop my problem solving skills as the problems which were given were similar to real life problems") as well as working with a team to meet to deadlines (" $P B L$ has developed my time management skills in a different way than I have ever used them, as it has been important to not only ensure that I meet deadlines, but the rest of the group as well" and "Working in a group and sticking to our schedule").

Responses to this questionnaire seem to support previous observations at Leicester that
C/PBL learning experiences play an important part in the development of students' transferable skills.

\section{Conclusions}

The mechanism used to deploy questionnaire 1 led to a good response rate. The responses to the questionnaires showed that the majority of respondents in both year groups rated all skills as being important or very important to chemists. The importance of most skills does not vary much between years one and two but there are small (non-statistically significant) increases in the levels of importance that students place on most transferable skills.

Responses to questionnaire 2 helped identify the skills which respondents believed were developed the most from the C/PBL experience ("problem solving", "time management", "working in a team" and "oral 
communication") and establish the fact that students believe specific aspects of the C/PBL approach contribute to this skills development (i.e. authentic assessment, contextualised "real-world" problems, group work and working to deadlines).

\section{References}

Belt S., Evans E. H., McCreedy T., Overton T. L., \& Summerfield S., (2002). A problem based learning approach to analytical and applied chemistry. University Chemistry Education, 6, 65-72.

Engel, C.E. (1997). Not Just a Method but a Way of Learning. In D, Boud. \& G, Feletti. (Eds.) The Challenge of Problem Based Learning. London: Kogan-Page.

Freeman, S., Eddy, S.L., McDonagh, M., Smith, M.K., Okoroafor, N., Jordt, H. \& Wenderoth, M.P. (2014). Active learning increases student performance in science, engineering and mathematics. Proceedings of the National Academy of Sciences of the United States of America (PNAS), 111(23), 8410-8415. doi: 10.1073/pnas.1319030111

Hanson, S. \& Overton, T. (2010), Skills Required by New Chemistry Graduates in Development of Degree Programmes, The Higher Education Academy, http://www.rsc.org/learn-

chemistry/resources/business-skills-andcommercial-awareness-for-

chemists/docs/skillsdoc1.pdf [Accessed 07 September 2016]

Honebein, P. C., Duffy, T. M. \& Fishman, B. J. (1993). Constructivism and design of learning environments: context and authentic activites for learning. In T.M. Duffy, J. Lowyck, \& D. H. Jonassen. (Eds.) Designing Environments for Constructive Learning. Berlin: Springer-Verlag.

Kelly, O. C. \& Finlayson, O. E. (2007). Providing solutions through problem-based learning for the undergraduate 1st year chemistry laboratory. Chemistry Education Research and Practice, 8(3), 347-361. doi: 10.1039/B7RP90009K
Lancaster, S. \& Read, D. (2013), Flipping lectures and inverting classrooms, Education in Chemistry, September 2013, 14-17

Raine, D. J. \& Symons, S. L. (2005). PossiBiLities a Practice Guide to Problembased Learning in Physics and Astronomy. Higher Education Academy, UK Physical Sciences Centre.

Savery, J.R. \& Duffy, T. M. (1995). Problem based learning: An instructional model and its constructivist framework. Educational Technology, 35(5), 31-38.

Sedghi, G. (2013), Peer assisted learning at the Department of Chemistry for home and international students, New Directions, 9 (1), 14-17. doi:10.11120/ndir.2013.00005

Seery, M. K. (2013), SELF-CHEM: Student Engagement in Learning Through Flipped Chemistry Lectures, DIT Learning, Teaching \& Technology Centre, 54-58

Summerfield, S., Overton, T. \& Belt, S. (2003), Problem-solving case studies. Analytical Chemistry, 75, 181-182. doi: Problem-solving case studies. Analytical Chemistry

Williams, D. P. (2015), "Problem Based Learning Approaches to Teaching Chemistry", in Blessinger, P. \& Carfora, J. M. (ed.) InquiryBased Learning for Science, Technology, Engineering, and Math (Stem) Programs: A Conceptual and Practical Resource for Educators (Innovations in Higher Education Teaching and Learning, Volume 4) Emerald Group Publishing Limited, pp.93 - 112. doi: 10.1108/S2055-364120150000004007

Williams, D. P. (2016), Creating an Assessment and Feedback Strategy for Problem Based Learning Chemistry Courses, Student Engagement in Higher Education Journal, 1 (1).

Williams, D. P., Woodward, J. R., Symons, S. L. \& Davies, D. L. (2010), A Tiny Adventure: the introduction of problem based learning in an undergraduate chemistry course, Chemical Education Research and Practice, 11, 33-42. doi: $10.1039 / \mathrm{c} 001045 f$ 